\title{
FLT3 Protein Variant
}

National Cancer Institute

\section{Source}

National Cancer Institute. FLT3 Protein Variant. NCI Thesaurus. Code C128920.

A variation in the amino acid sequence for the receptor-type tyrosine-protein kinase FLT3 protein. 